\title{
Simulations of the Crude Oil Tank Refurbishment Project Risks Using Monte Carlo
}

\author{
Ari Sandhyavitri1,* (1) , Arvin ${ }^{1}$, Fajar Restuhadi2 ${ }^{2}$ \\ ${ }^{1}$ Civil Engineering Department, University of Riau, Pekanbaru, 28293, Indonesia \\ ${ }^{2}$ Agribusiness Department, University of Riau, Pekanbaru, 28293, Indonesia
}

\begin{abstract}
Simulation technology has assisted project stakeholders in predicting a range of project results in the future under risks and uncertainties. The objectives of this article are to improve comprehensive project planning in the perspective of the project schedule by conducting simulations for the refurbishment of crude oil tank project risks using Monte Carlo simulations. The practical approaches for simulating the risks encompassed 3 stages: risk identification, assessment, and risk analysis using the Monte Carlo simulations. The implementation of Monte Carlo simulation in the form of a stochastic approach however was not new, but the application of these approaches in the area of oil industrial projects was challenging. A Free Water Knock-Out (FWKO) tank project located in Duri, Indonesia was taken as a case study. The initial FWKO project duration was set up to be 180 working days, and it was delayed (up to $140 \%$ from the initial duration of the project planning). This study conducted deep questioner surveys from 25 oil industry stakeholders. It was identified 29 risk factors have been considered as the major causes of the project delay. The risk factors were then calculated qualitatively for performing risk indexes. Based on the risk simulations (after 1000 iterations) using Monte Carlo simulations utilizing @risk application package (under uncertainties) there was found that the possibility of this project would experience delays at the range of 47 days (126\%) to 80 days (144\%) from the initial project planning. This simulation had also identified the most sensitive activities causing project delays. The results were presented in the form of the spider graph diagram which assisted the project stakeholders in developing a strategic decision during the project planning phase.
\end{abstract}

Key words: delay; Monte Carlo simulation; refurbishment; risk analyses; oil tank.

\section{INTRODUCTION}

Over the years, various risk factors of project delays in the construction industry have been reviewed from many articles such as [1-7].

Limited articles have simulated the risk assessment for the crude oil tank refurbishment projects in the light of qualitative and stochastic approaches using risk analyses application packages [8]. Hence, it is a challenge to identify, assess and simulate risks of delays in the oil tank refurbishment projects based on the stochastic methods for better understanding managing of risks in the area of the oil industry around the world. The simulation of stochastic models was developed for estimating and predicting a range of output values under certain operational conditions suited to industrial purposes under uncertainty $[7,9]$.

These article objectives were to; (i) identify risk factors causing project delay, (ii) establish a list of risk indexes, and (iii) simulate the risks using Monte Carlo simulations as well as the sensitivity risks.

The refurbishment of the existing crude oil tank project or Free Water Knock out (FWKO) project in Duri oil gathering station, Sumatra Island, Indonesia was taken as a case study in this article. There were more than 50 similar crude oil tanks in needed to be repaired and replaced shortly in Indonesia [10]. This article is expected may assist the project owner and constructors in developing a strategic decision (during the project planning phase) for analyses of risks in similar FWKO projects in the future.

This study performed risk analyses procedures as follows; (i) risk identification for establishing a risks list, (ii) risk assessment for quantifying risks, and (iii) risk analyses (Figure 1) [11, 12].

The risk identification was performed by distributing a list of questioners to the FWKO stakeholders. The lists of questionnaires were then analyzed utilizing Likert scales for measuring the probability magnitude of; (i) the risk frequencies, and (ii) risk impacts [13]. The frequency doesn't need to be directly proportional to the impact, for example, the impact of lack of work safety procedures during construction was relatively high, but the frequency to occur was relatively so-so. The risk frequency and impact scales were also summarized in Table 1.

$\begin{array}{ll}\text { Received } & \text { : July 17, 2021 } \\ \text { Revised } & \text { : December 12, 2021 } \\ \text { Accepted } & : \text { February 02, 2022 }\end{array}$




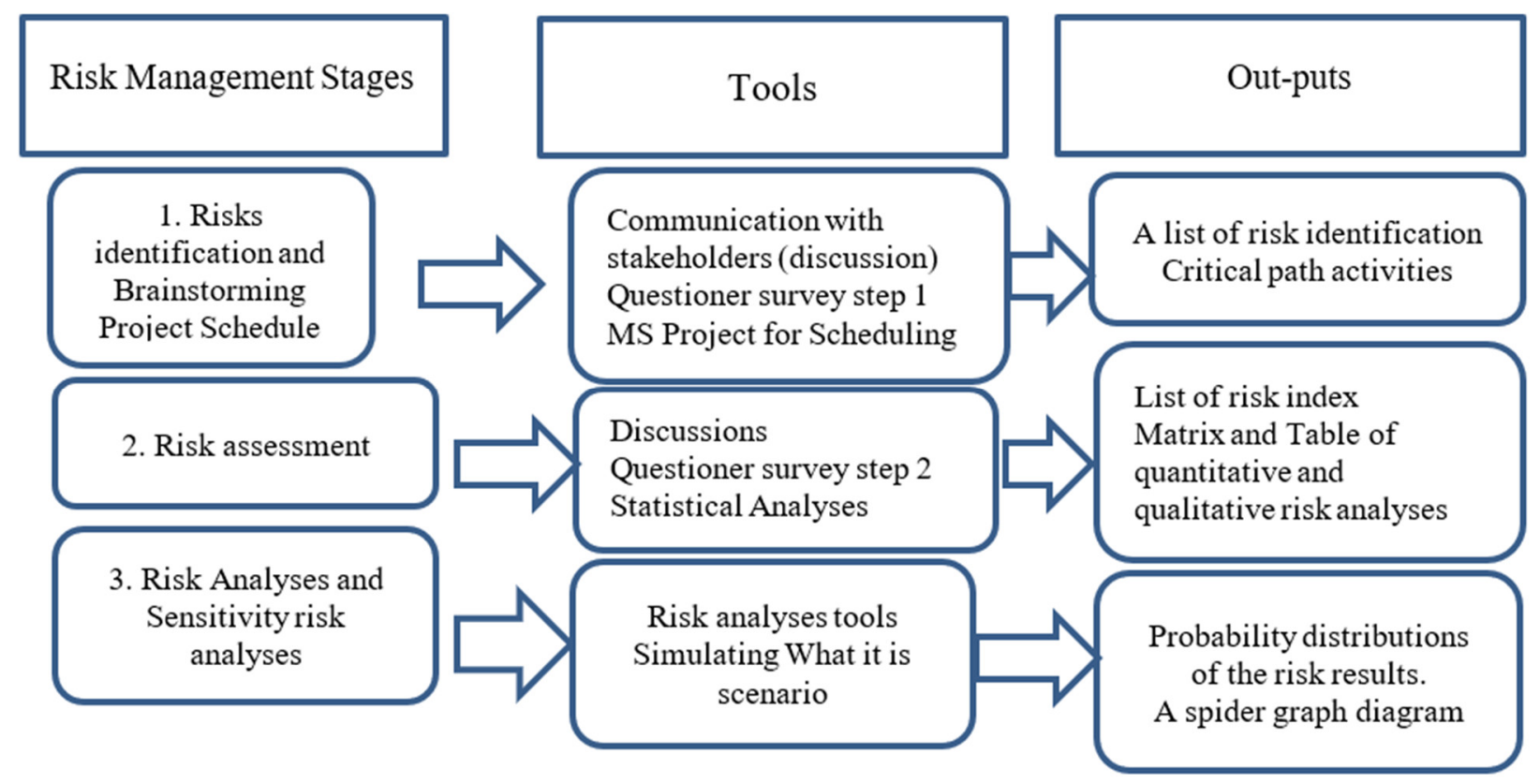

Fig. 1. Three Stages of Risk Analyses Procedure

Table 1. Risk Frequency and Impact

$\begin{array}{ccrr}\text { Scale } & \text { Value } & \text { Frequency (A) } & \text { Impact (B) } \\ 1 & 0.00 & \text { Never occur } & \text { Very low } \\ 2 & 0.25 & \text { Rarely } & \text { Low } \\ 3 & 0.50 & \text { Frequent } & \text { Moderate } \\ 4 & 0.75 & \text { Very frequent } & \text { High } \\ 5 & 1.00 & \text { Absolutely occur } & \text { Very high }\end{array}$

Then, risk assessments were performed to classify risk according to their index. The risk index was classified into three simple main categories $[7,11]$ as follow:

- The low-risk category was calculated as a very low to low relative risk importance index. The low risk is considered insignificant to cause project delay. This is because the frequency of the risk occurrences was relatively low and so does the impact.

- The medium-risk category is considered as either its frequency or impact is relatively moderate or high. It is considered to take any necessary plans for controlling the risks (as long as there are adequate resources provided for mitigating the risks); and

- The high-risk category is calculated as the frequency of the risk occurrence and the impacts are relatively high or very high. It is recommended to perform risk mitigation procedures for minimizing the potential risk occurrences [11].

A sensitivity risk analysis was also performed to describe uncertainties in the output model which were affected by the different uncertainties in the input model in the form of a spider graph. The sensitivity analyses are commonly performed for estimating a range of probable project schedules or revenue generations, and other feasibility study parameters $[14,15]$.
The application of @risk is an add-in to Microsoft Excel was utilized for simulating this case study. This application could simulate and analyze risk using Monte Carlo simulation which presents graphically all possible outcomes of the designated results (for example project durations, and costs) $[16,17]$.

\subsection{Why Monte Carlo Simulations}

Monte Carlo simulations are one of the risk analysis methods relying on repeated random sampling using statistical analysis to yield probable results [18]. A Monte Carlo simulation is also well known as "what-if analysis" [19-21].

The advantages of using Monte Caro simulations compared to the deterministic model were that the input variables for the models depend on the variation of the external and internal conditions. The probability risk analyses are also dynamic and able to yield different results for the different inputs model, once the model is simulated $[20,22]$.

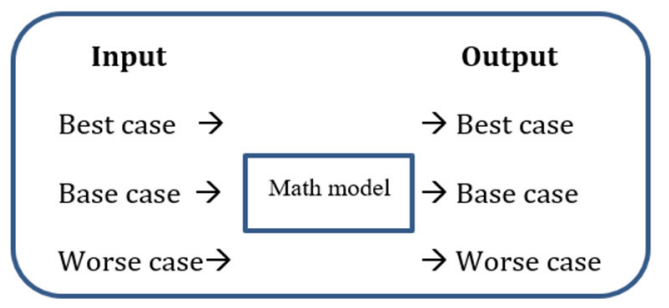

Fig. 2. Case-based models [21].

Based on literature reviews the utilization of this Monte Carlo simulation has improved quantitative project analysis for developing decisions [16, 19-21].

\section{METHODOLOGY}

The methods applied in this study are following these 3 steps ; (i) Establishing questionnaire surveys to identify a list of risk factors that may occur in this project, (ii) assessing 


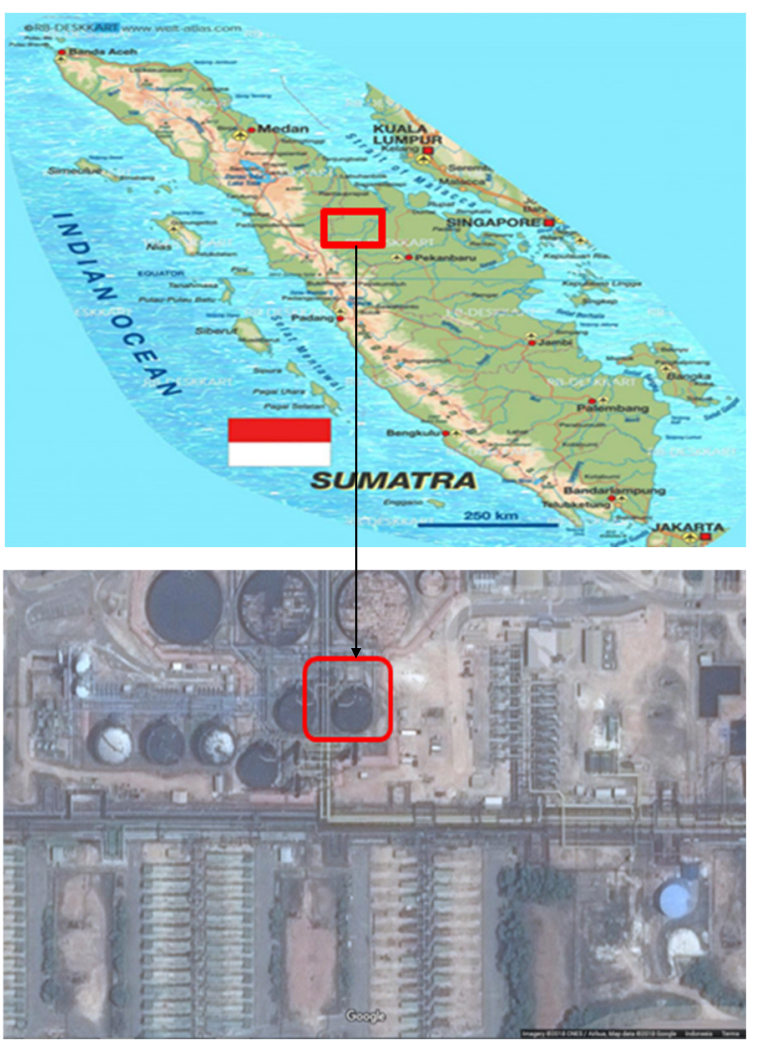

(a)

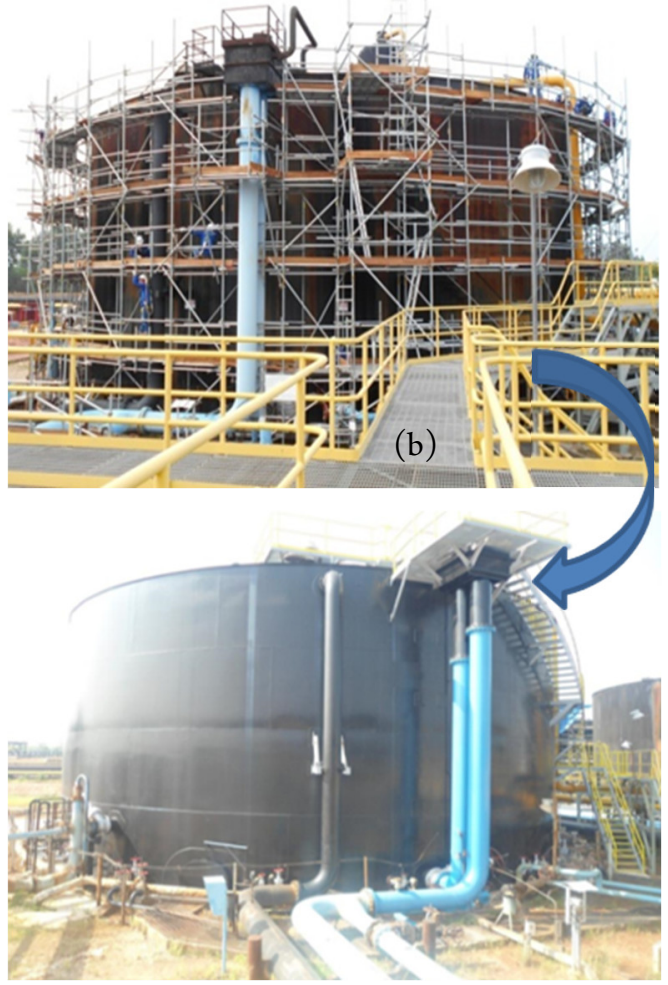

(c)

Fig. 3. (a) project location, (b) crude oil tank refurbishment in progress, (c) crude oil final construction

for quantifying the risk frequency and its impact causing the project delays by conducting qualitative risk analyses procedures, and (iii) performing a sensitivity risk analysis (Figure 1).

\subsection{Conducting Survey}

In order to identify a list of risk factors, this study conducted a field questionnaire survey from several project stakeholders [23]. This study conducted $1^{\text {st }}$ questionnaire survey by interviewing 25 respondents consisting of 1 respondent from the project owner, 12 respondents from the supervisory consultant, and 12 respondents from the project contractor. This research applied Disproportional Stratified Random Sampling (DSRS). The Disproportional Stratified Random Sampling divided the population into strata and selected a simple random sample from each stratum. The sample represents the characteristics of the total population [18].

\subsection{Performing Risk Assessment}

A Qualitative Risk Assessment was performed by conducting a questionnaire survey. The questioners were designed to quantify risk frequency and its impact causing project delays (by conducting the $2^{\text {nd }}$ Questioner Survey), and the collected data were analyzed using qualitative analyses $[24,25]$. This $2^{\text {nd }}$ questionnaire survey was also conducted to validate a list of risk factors based on a Lickert scale using 1 to 5 scales [13].

\subsection{Performing Risk Analyses}

Risk analyses were performed by simulating the existing input data using "what it is scenario". The risk simulation results were presented in the form of Probability Distribution Function (PDF) and Cumulative of Distribution Function (CDF) graphs. The results would be conducted after running 1000 times iterations.

In this article, a spider graph diagram was used to illustrate the sensitivity of the project delay over the project activities. The final results were drawn in the form of probability distributions graphs using Monte Carlo simulation utilizing @risk software package [16], [17].

\subsection{Refurbishment of Oil Tank Projects}

A refurbishment of the oil tank project is defined as a partial or an overall replacement activity package related to the tank structures and facilities [8].

The refurbishment project may encompass various activities, with a high degree of complexity, and uncertainty including integrative demolition of the existing tank, and construction of the new one within a small and narrow working area $[10,26]$.

It was reported that the existing tanks within the Duri oil field were operated for more than 40 years and are in urgent need to be repaired as there has been corrosion and thinning undergone inside and outside the tank plates. In this case study, the tank's diameter dimension was $22 \mathrm{~m}$ in height was $9.6 \mathrm{~m}$ with a tank capacity of 21.9 thousand barrels of crude oil (Figure $3(b, c)$ ).

Again the results of this case study may be a reference for the oil industry stakeholders in managing the risk of delay in this tank oil refurbishment project in the near future. The location of the FWKO project and the condition of the existing tank were presented in Figure 3 (a). 


\section{RESULTS AND DISCUSSIONS}

\subsection{Free Water Knock out (FWKO) Refurbishment Project}

The refurbishment FWKO activities in Duri consisted of at least 4 main packages encompass; (i) tank cleaning activities, (ii) dismantling of ring wall and tank bottom plat, (iii) installation of tank bottom plate and shell, and (iv) installation of the center column and tank roof. The total number of FWKO sub-activities (level 3) may include 54 activities.

\subsection{Stage 1. Risks identification and Brainstorming of the Project Schedule}

It was identified, 16 main activities existed in the critical path of the FWKO project.

The initial schedule for accomplishing this project was designated for 180 days. During the construction phase, it was calculated that the actual duration became 437 days (delayed for 257 days or almost $250 \%$ from the initial project duration) In this paper, the terminology of working days, later on, will be defined as "days" only.

Based on the literature review, it was identified that there were approximately 30 to 49 risk factors inherent in the type of oil project $[6,7,27]$.

This study conducted deep questioner surveys to the oil stakeholders in the restricted oil industry areas for identification of a range of risk input for conducting risk analyses using the Monte Carlo simulations $[19,26]$.

To obtain a list of risk factors, the identified risk frequencies and risk impacts were then multiplied. The results of the multiplication of risk frequencies and impacts $=$ risk index. The risk index can be seen in Table 3 and Figure 7. The risk analysis was then listed based on the Risk Index $[11,12]$. This index is presented as follow:

$$
\mathrm{R}=\mathrm{I} \times \mathrm{P}
$$

Where: $\mathrm{R}=$ Risk index,I = Risk probability (frequency), $\mathrm{P}=$ Risk impact.

The $2^{\text {nd }}$ questionnaire survey data were analyzed using the SPSS application package to perform the validation test. Based on the phase II questionnaire survey data, then the multiplication between the frequency of risk events and the impact of the risks that occur for each single risk index for the delay was calculated and validated.

This article illustrated 9 the highest list of the risk indexes causing the delays (based on their total correlations). These risk indexes encompass; (i) poor coordination among the project parties (X8), (ii) Lack of experienced human resources (X15), (iii) Lack of supervisors quality (X16), (iv) inadequate work safety procedures during construction (X17), (v) Lack of construction equipment (X20), (vi) limited and narrow working area (X21), (vii) design changes during construction (X24), (viii) the difficulty in obtaining daily work permits (X26), and (ix) A complicated inter-dependencies critical path activities (X27).

The risks were then indexed into 3 simple levels (encompassing minimum, medium, and maximum). The maximum risk index level was 0.568 , with the minimum average value was 0.178 , and the range value $=0.390$.

The average distance of the value is $0.390 / 3=0.130$ (as there was assumed that the risk index would be classified into 3 categories; low, medium, and high). This low risk range value $=0.178+0.130=0.308$, medium $=0.308+0.130=$ 0.438 , and high $=0.438+0.130=0.568$ (Figure 4$)$.

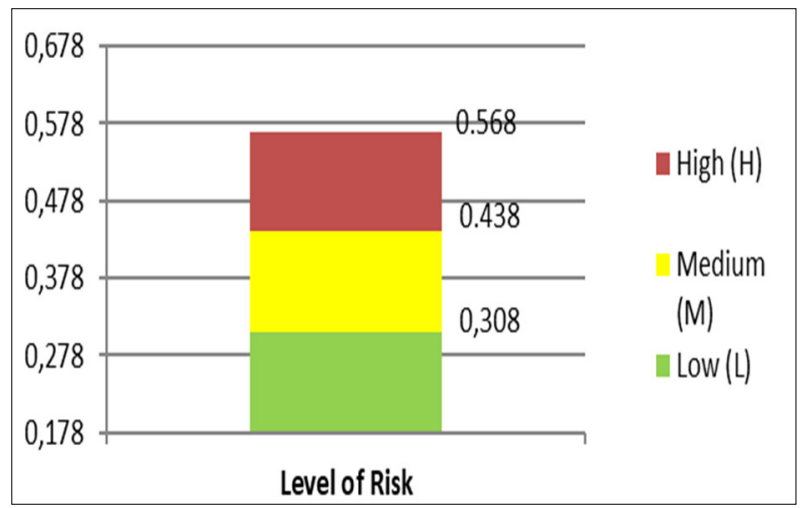

Fig. 4. Level of Risk

\subsection{Stage 3. Simulating Risks by Conducting Risk Analyses and Sensitivity Analyses}

In this article the risk simulations were implemented by conducting; (i) risks analyses, and (ii) sensitivity analyses.

(i) Risk Analyses (What it is Scenario)

Risk analyses were performed using the distribution of the input values of the project risks which were obtained from the $2^{\text {nd }}$ survey data.

A Monte Carlo simulation using Pert Distribution was applied for calculating the duration of project activities (with a minimum duration of 165 days, most likely to be 180 days and a maximum of 437 days).

For example, historically based on the initial project planning the duration for installation of water column activities was estimated 24 days (most likely duration), in practice, these activities were conducted in 38 days (maximum one) and the minimum duration for performing these activities would be 24 days $\mathrm{x}(100 \%$ - a base value of the minimum risk of $17.8 \%)=20$ days (Table 2 ). Based on 3rd surveys the delay was identified as the cause of various risk factors such as; poor coordination among the project parties in the construction of water column (X8), lack of supervisor quality in managing the activities (X16), inadequate construction equipment within the project location (X20), narrow working area (X21).

Table 2 shows that there were 3 main columns encompass, initial planning duration (days), a 3-point estimate before conducting risk mitigation procedures (in percentage), and a 3-point estimate before conducting risk mitigation procedures (days).

After performing simulation for scenario 1 using Palisade Decision Tool @risk application package utilizing Table 2 data, with 1000 iterations, it was identified that there was a $90 \%$ probability the total duration of the project would be accomplished in the range of 227 days to 260 days. There was also an $80 \%$ probability the project could be accomplished in 250 days (Figure 5). However, the total maximum duration would be 437 days (Table 2). 
Table 2. Three estimated durations before conducting mitigation process

\begin{tabular}{|c|c|c|c|c|c|c|c|c|}
\hline \multirow[t]{2}{*}{ No } & \multirow[t]{2}{*}{ Activities } & \multirow{2}{*}{$\begin{array}{l}\text { Initial Plan } \\
\text { (Duration) }\end{array}$} & \multicolumn{3}{|c|}{$\begin{array}{l}\text { 3-point estimate duration before } \\
\text { conducting risk mitigation } \\
\text { procedures }(\%)\end{array}$} & \multicolumn{3}{|c|}{$\begin{array}{c}\text { 3-point estimates duration before } \\
\text { conducting risk mitigation p } \\
\text { rocedures (days) }\end{array}$} \\
\hline & & & Minimum & $\begin{array}{l}\text { Most } \\
\text { Likely }\end{array}$ & Maximum & Minimum & $\begin{array}{l}\text { Most } \\
\text { Likely }\end{array}$ & Maximum \\
\hline \multicolumn{9}{|c|}{ 4. Construction } \\
\hline & Install Center Column and Rafter & 24 & $82.20 \%$ & $100 \%$ & $158.33 \%$ & 20 & 24 & 38 \\
\hline & Welding Bottom to Annular (Partial) & 6 & $82.20 \%$ & $100 \%$ & $183.33 \%$ & 5 & 6 & 11 \\
\hline & Remove \& Install Rib Rafter & 4 & $82.20 \%$ & $100 \%$ & $775.00 \%$ & 4 & 4 & 31 \\
\hline & Install Rafter & 8 & $82.20 \%$ & $100 \%$ & $162.50 \%$ & 7 & 8 & 13 \\
\hline & Install Roof & 19 & $82.20 \%$ & $100 \%$ & $147.37 \%$ & 16 & 19 & 28 \\
\hline & Fit-Up Roof & 6 & $82.20 \%$ & $100 \%$ & $200.00 \%$ & 5 & 6 & 12 \\
\hline & Welding Roof & 7 & $82.20 \%$ & $100 \%$ & $200.00 \%$ & 6 & 7 & 14 \\
\hline & Install Water Legs & 7 & $82.20 \%$ & $100 \%$ & $442.86 \%$ & 6 & 7 & 31 \\
\hline & Install Water Leg Box & 3 & $82.20 \%$ & $100 \%$ & $700.00 \%$ & 3 & 3 & 21 \\
\hline & Install Platform Water Legs & 4 & $82.20 \%$ & $100 \%$ & $275.00 \%$ & 4 & 4 & 11 \\
\hline & Install SID and Accessories & 4 & $82.20 \%$ & $100 \%$ & $500.00 \%$ & 4 & 4 & 20 \\
\hline & Install Sid 2 & 5 & $82.20 \%$ & $100 \%$ & $200.00 \%$ & 5 & 5 & 10 \\
\hline & Install Roof Platform & 5 & $82.20 \%$ & $100 \%$ & $540.00 \%$ & 5 & 5 & 27 \\
\hline & Internal Tank & 7 & $82.20 \%$ & $100 \%$ & $242.86 \%$ & 6 & 7 & 17 \\
\hline & Sand Blasting Coat Shell & 7 & $82.20 \%$ & $100 \%$ & $171.43 \%$ & 6 & 7 & 12 \\
\hline & Prime Coat Shell & 5 & $82.20 \%$ & $100 \%$ & $200.00 \%$ & 5 & 5 & 10 \\
\hline & Roof (Top Layer) & 3 & $82.20 \%$ & $100 \%$ & $300.00 \%$ & 3 & 3 & 9 \\
\hline & Final Shell & 4 & $82.20 \%$ & $100 \%$ & $250.00 \%$ & 4 & 4 & 10 \\
\hline & Remove Cover Sheet & 2 & $82.20 \%$ & $100 \%$ & $200.00 \%$ & 2 & 2 & 4 \\
\hline & Touch Up Roof and Bottom & 3 & $82.20 \%$ & $100 \%$ & $166.67 \%$ & 3 & 3 & 5 \\
\hline & Touch Up SID and Accessories & 3 & $82.20 \%$ & $100 \%$ & $166.67 \%$ & 3 & 3 & 5 \\
\hline & Close Door sheet & 5 & $82.20 \%$ & $100 \%$ & $100.00 \%$ & 5 & 5 & 5 \\
\hline & Install Plate for Door Sheet & 1 & $82.20 \%$ & $100 \%$ & $200.00 \%$ & 1 & 1 & 2 \\
\hline & Welding Door Sheet & 2 & $82.20 \%$ & $100 \%$ & $150.00 \%$ & 2 & 2 & 3 \\
\hline & Inspection & 2 & $82.20 \%$ & $100 \%$ & $100.00 \%$ & 2 & 2 & 2 \\
\hline & Punch list & 5 & $82.20 \%$ & $100 \%$ & $160.00 \%$ & 5 & 5 & 8 \\
\hline & Hydro test Tank & 7 & $82.20 \%$ & $100 \%$ & $142.86 \%$ & 6 & 7 & 10 \\
\hline & Hydro test Preparation & 1 & $82.20 \%$ & $100 \%$ & $200.00 \%$ & 1 & 1 & 2 \\
\hline & Filling water and Settlement (25\%) & 1 & $82.20 \%$ & $100 \%$ & $200.00 \%$ & 1 & 1 & 2 \\
\hline & Filling water and Settlement (50\%) & 1 & $82.20 \%$ & $100 \%$ & $200.00 \%$ & 1 & 1 & 2 \\
\hline & Filling water and Settlement (100\%) & 1 & $82.20 \%$ & $100 \%$ & $200.00 \%$ & 1 & 1 & 2 \\
\hline & Holding time \& release & 2 & $82.20 \%$ & $100 \%$ & $100.00 \%$ & 2 & 2 & 2 \\
\hline & Install all exiting spools & 2 & $82.20 \%$ & $100 \%$ & $1500,0 \%$ & 2 & 2 & 30 \\
\hline & Finishing Work & 4 & $82.20 \%$ & $100 \%$ & $250.00 \%$ & 4 & 4 & 10 \\
\hline & Dismantle Scaffolding & 3 & $82.20 \%$ & $100 \%$ & $166.67 \%$ & 3 & 3 & 5 \\
\hline & House Keeping & 2 & $82.20 \%$ & $100 \%$ & $200.00 \%$ & 2 & 2 & 4 \\
\hline & Delivery Existing Material to Junk Yard & 2 & $82.20 \%$ & $100 \%$ & $200.00 \%$ & 2 & 2 & 4 \\
\hline & PSSR (Pre Safety Start-Up) & 2 & $82.20 \%$ & $100 \%$ & $150.00 \%$ & 2 & 2 & 3 \\
\hline & Total duration & 180 & & & & 165 & 180 & 437 \\
\hline
\end{tabular}



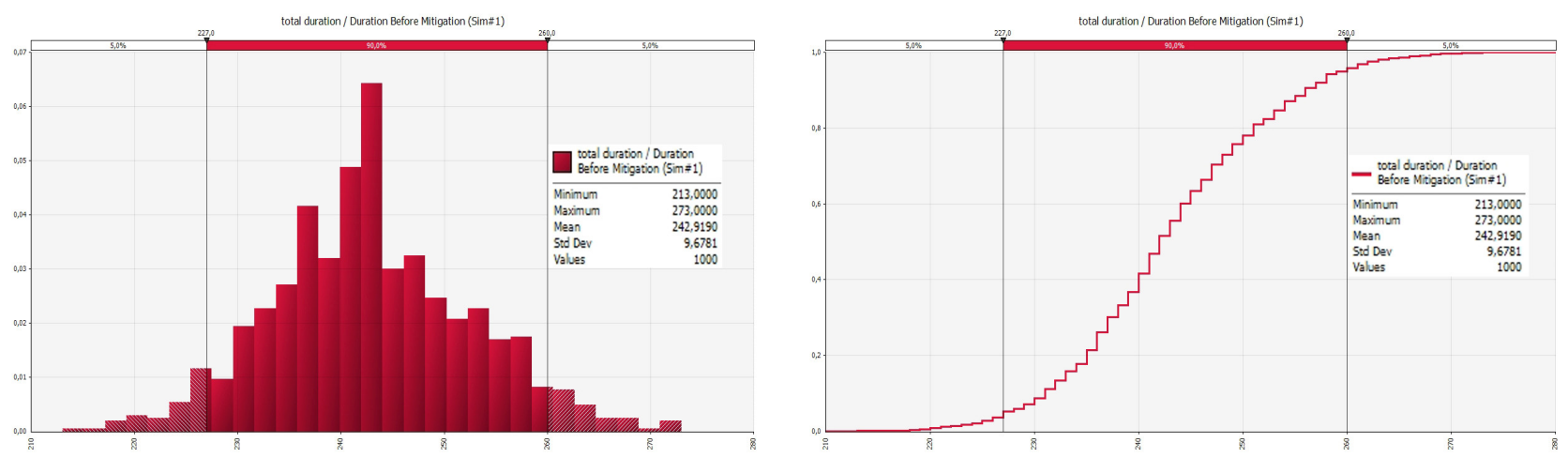

Fig. 5. Probability Distribution Function Graph (PDF) and Cumulative of Distribution Function (CDF) Graph of the total duration activities Before Mitigation

Table 3. Head to head of estimated project durations in 3 conditions (initial plan schedule, actual schedule, and simulation

\begin{tabular}{clll}
\hline No & Conditions & Completion Duration & Notes \\
\hline 1 & Initial plan & 180 days & $\begin{array}{l}\text { Determined the estimated project duration } \\
\text { without predicting and identification of any } \\
\text { risks inherent in the project. }\end{array}$
\end{tabular}

2 Actual 437 days

Implementing the project without conducting any simulation of the probability of the project delay and risks.

3 Simulation ( $90 \%$ probability) at the range of 227 days to 260 days

Simulating the project duration using Monte Carlo and considering the uncertainty as well as project risks.

The initial project duration was 180 days. There was the possibility of this project would experience delays from 47 days to 80 days (126\%-144\%). And there was a $0 \%$ probability for accomplishing the project duration (at 180 days) under those identified project risk and uncertainty conditions. Hence, based on these findings the project owner and managers may evaluate their schedule and working process for performing tank refurbishment projects in the future systematically achieving the project objectives.

Table 3 shows that there were 3 different results for completing the project schedule. At the initial plan, there was estimated that the project would be accomplished in 180 days using deterministic analyses without considering any risks inherent in the FWKO project. In fact, the project had been finished in 473 days. Hence, it is necessary to calculate the project duration using simulations in order to yield a comprehensive result. Based on the implementation of Monte Carlo simulations running on @risk application package it was calculated that the project duration would be in the range of 227 days to 260 days.

\section{(ii) Developing Sensitivity Risk Analyses}

Claudia Hermeling and Tim Mennel, 2008 highlighted the important roles of sensitivity analysis in the technical and economic perspectives [28]. After conducting a simulation utilizing table 2 data using @risk application, it was identified 8 main activities contributing significantly to the project delays such as; installation of the existing spools activity, installing water leg, installing roof platform, etc.
(Figure 6). The more sensitive the activity, the more its effect to change output results (causing project delay). For example, the change in the duration for installing all the existing spools activity at $35 \%$ may affect to increase the total project delay up to $10 \%$, and the additional duration in removing and installing rib rafter $25 \%$ will contribute to $9 \%$ of the total project delay.

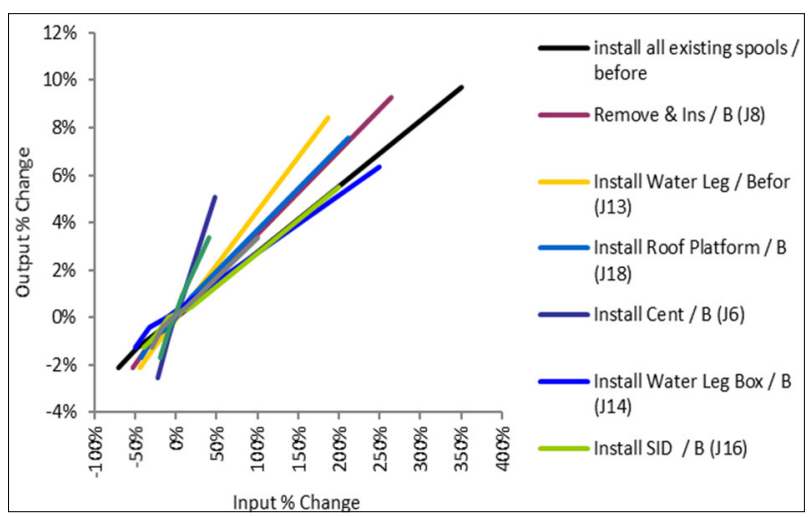

Fig. 6. Spider graph before conducting risk mitigation

The list of sensitive activities in this article highlights the most sensitive activities that affect project delay. The list of activities was as the following order; install all existing spools, remove \& install rib rafter, install water leg, install roof platform, install the center column and rafter, install water leg box, install (safety in design) SID equipment, install the roof, and internal tank (Figure 6). Thus, it is 
important to pay attention to evaluating and mitigating these 8 sensitive activities for controlling and reducing the risk impacts in the future.

\section{CONCLUSION}

Based on the Monte Carlo simulations, there was a 90\% probability total duration for completing the project was in the range of $124 \%-144 \%$ from the total initial project schedule. It stated that there was no chance for completing the project schedule within 180 days (the initial project planning). Hence, it proves that implementing the project simulation using @risk application package using the Monte Carlo risk analyses yielded a range of estimated output values (of the project delay) under the uncertainties. These results become a basis of the project owner and managers prior to developing comprehensive strategic planning for the refurbishment of oil tanks in the future.

\section{AUTHOR INFORMATION}

\section{Corresponding Author}

*Email: ari.sandhyavitri@eng.unri.ac.id

\section{ORCID}

Ari Sandhyavitri : 0000-0002-3174-5502

\section{ACKNOWLEDGMENT}

The author would like to thank the PT Chevron Pacific Indonesia, the Civil Engineering Department University of Riau, Rizki Ramadhan Husain, and the team for assisting the author in supporting this research study.

\section{REFERENCES}

[1] Y. Frimpong, J. Oluwoye, and L. Crawford, "Causes of delay and cost overruns in construction of groundwater projects in a developing countries; Ghana as a case study," Int. J. Proj. Manag., vol. 21, no. 5, pp. 321-326, 2003, doi: 10.1016/S0263-7863(02) 00055-8.

[2] S. A. Assaf and S. Al-Hejji, "Causes of delay in large construction projects,” Int. J. Proj. Manag., vol. 24, no. 4, pp. 349-357, 2006, doi: 10.1016/ j.ijproman.2005.11.010.

[3] A. Kazemi, "Causes of delay in construction projects: The case he case of oil and gas projects," vol. 4, no. 1, pp. 11-16, 2018, doi: 10.24178/ijare.2018.4.1.11.

[4] A. Kazemi, A. Nemat-Gorgani, and S. Aryaee, "Delay in Oil Projects: Review of Past Developments and Provide a Model for Predicting Delay Time-Case Study: EPC Projects of the POGC," J. Manag. Improv., vol. 13, no. 4, pp. 147-164, 2020, [Online]. Available : https://www.sid.ir/FileServer JF/4010413984605.

[5] I. Mahamid, "Common risks affecting time overrun in road construction projects in palestine: Contractors' perspective," Australas. J. Constr. Econ. Build., vol. 13, no. 2, pp. 45-53, 2013, doi: 10.5130/ ajceb.v13i2.3194.

[6] M. Salama, M. Abd, E. Hamid, and B. Keogh, "INVESTIGATING THE CAUSES OF DELAY
WITHIN OIL AND GAS PROJECTS IN THE U . A . E.,” no. September, pp. 819-827, 2008.

[7] A. Sandhyavitri, "Stochastic analyses for managing risk of delay in Duri oil construction projects, Indonesia," Int. J. Constr. Manag., 2019, doi: 10.1080/15623599.2019.1644762.

[8] J. Reyers and J. Mansfield, "The assessment of risk in conservation refurbishment projects," Struct. Surv., vol. 19, no. 5, pp. 238-244, Jan. 2001, doi: 10.1108/02630800110412480.

[9] K. S. Bouayoune, E. M. Boudi, and A. Bachir, "A stochastic method based on the Markov Model of unit jump for analyzing crack jump in a material," Int. J. Technol., vol. 8, no. 4, pp. 622-633, 2017, doi: 10.14716/ijtech.v8i4.9480.

[10] Arvin Arvin, "A Free Water Knock-Out (FWKO) Tank Project Report, Duri, Indonesia.,” Duri, 2018.

[11] Project Management Institute, A Guide to the Project Management Body of Knowledge (PMBOK ${ }^{\circledR}$ Guide) - Fifth Edition, I. 2013.

[12] S. Mohamad, M. Langeroodi, R. Ehsani, and N. Hamidi, "Presentation of a Conceptual Framework for Risk Management of Construction Projects Based on PMBOK Standard (With Case Study)," Middle-East J. Sci. Res., vol. 9, no. 6, pp. 797-806, 2011.

[13] A. Joshi, S. Kale, S. Chandel, and D. Pal, "Likert Scale: Explored and Explained," Br. J. Appl. Sci. Technol., vol. 7, no. 4, pp. 396-403, 2015, doi: 10.9734/ bjast $/ 2015 / 14975$.

[14] A. Saltelli, "Sensitivity analysis for importance assessment,” Risk Anal., vol. 22, no. 3, pp. 579-590, 2002, doi: 10.1111/0272-4332.00040.

[15] E. K. Zavadskas, Z. Turskis, and J. Tamošaitiene, "Risk assessment of construction projects," J. Civ. Eng. Manag., vol. 16, no. 1, pp. 33-46, Jan. 2010, doi: 10.3846/jcem.2010.03.

[16] Palisade 2, @ RISK for Six Sigma, no. 607. 798 Cascadilla St. Ithaca, NY USA 14850: Palisade Corporation. Trademark, 2007.

[17] Palisade 1, Guide to Using @Risk, vol. 5.5. Palisade Corporation 798 Cascadilla St. Ithaca, NY USA 14850 (607): Palisade Corporation, 2010.

[18] S. Belouafa et al., "Statistical tools and approaches to validate analytical methods: Methodology and practical examples," Int. J. Metrol. Qual. Eng., vol. 8, 2017, doi: $10.1051 /$ ijmqe/2016030.

[19] D. Frenkel, Introduction to Monte Carlo Methods Daan Frenkel, vol. 23, no. 1. Computational Soft Matter: From Synthetic Polymers to Proteins, Lecture Notes, 2004.

[20] Y. H. Kwak and L. Ingall, "Exploring monte carlo simulation applications for project management," IEEE Eng. Manag. Rev., vol. 37, no. 2, pp. 84-90, 2009, doi: $10.1109 /$ emr.2009.5235458.

[21] S. Raychaudhuri, "Introduction to monte carlo simulation,” Proc. - Winter Simul. Conf., pp. 91-100, 2008, doi: 10.1109/WSC.2008.4736059.

[22] C. Muriana and G. Vizzini, "Project risk management: A deterministic quantitative technique for assessment and mitigation," Int. J. Proj. Manag., vol. 35, no. 3, pp. 
320-340, 2017, doi: 10.1016/j.ijproman.2017.01.010.

[23] A. Mills, "A systematic approach to risk management for construction," Struct. Surv, vol. 19, no. 5, pp. 245-252, 2001, doi: 10.1108/02630800110412615.

[24] Y. Vacanas, "The risk of delay in Cyprus construction industry: causes, effects and control." 2018.

[25] A. Saltelli, S. Tarantola, F. Campolongo, and M. Ratto, Sensitivity analysis in practice: a guide to assessing scientific models (Google eBook). 2004.

[26] G. Guangdong SGIS Songshan Co Ltd, "Gas Tank Project: Environmental Impact Assessment Repor," no. May, pp. 1-197, 2008.
[27] A. Kazemi, A. Katebi, and M. Kazemi, "Identifying causes of delay in oil and gas construction projects using fuzzy delphi method," 3rd Int. Conf. Actual Econ. Soc. Probl. Mod. Glob., no. 2013, pp. 2017-214, 2018.

[28] T. M. Claudia Hermeling, "Sensitivity analysis in economic simulations -a systematic approach," Mannheim, Germany, 2008. 